University of Nebraska - Lincoln

DigitalCommons@University of Nebraska - Lincoln

USDA Forest Service / UNL Faculty Publications U.S. Department of Agriculture: Forest Service -National Agroforestry Center

2012

\title{
Modeling broad-scale patterns of avian species richness across the Midwestern United States with measures of satellite image texture
}

\author{
Patrick D. Culbert \\ University of Wisconsin \\ Volker C. Radeloff \\ University of Wisconsin \\ Véronique St-Louis \\ University of Minnesota \\ Curtis H. Flather \\ Rocky Mountain Research Station \\ Chadwick D. Rittenhouse \\ University of Wisconsin \\ See next page for additional authors \\ Follow this and additional works at: https://digitalcommons.unl.edu/usdafsfacpub \\ Part of the Forest Sciences Commons
}

Culbert, Patrick D.; Radeloff, Volker C.; St-Louis, Véronique; Flather, Curtis H.; Rittenhouse, Chadwick D.; Albright, Thomas P.; and Pidgeon, Anna M., "Modeling broad-scale patterns of avian species richness across the Midwestern United States with measures of satellite image texture" (2012). USDA Forest Service / UNL Faculty Publications. 156.

https://digitalcommons.unl.edu/usdafsfacpub/156

This Article is brought to you for free and open access by the U.S. Department of Agriculture: Forest Service -National Agroforestry Center at DigitalCommons@University of Nebraska - Lincoln. It has been accepted for inclusion in USDA Forest Service / UNL Faculty Publications by an authorized administrator of DigitalCommons@University of Nebraska - Lincoln. 
Authors

Patrick D. Culbert, Volker C. Radeloff, Véronique St-Louis, Curtis H. Flather, Chadwick D. Rittenhouse, Thomas P. Albright, and Anna M. Pidgeon 


\title{
Modeling broad-scale patterns of avian species richness across the Midwestern United States with measures of satellite image texture
}

\author{
Patrick D. Culbert ${ }^{\mathrm{a}, *}$, Volker C. Radeloff a , Véronique St-Louis ${ }^{\mathrm{b}}$, Curtis H. Flather ${ }^{\mathrm{c}}$, \\ Chadwick D. Rittenhouse ${ }^{a}$, Thomas P. Albright ${ }^{d}$, Anna M. Pidgeon ${ }^{a}$ \\ a Department of Forest and Wildlife Ecology, University of Wisconsin, Madison, WI 53706, USA \\ ${ }^{\mathrm{b}}$ Department of Fisheries, Wildlife, and Conservation Biology, University of Minnesota, St. Paul, MN 55108, USA \\ c USDA, United States Forest Service, Rocky Mountain Research Station, Ft. Collins, CO 80526, USA \\ d Department of Geography, University of Nevada, Reno, NV 89557, USA
}

\section{A R T I C L E I N F O}

\section{Article history:}

Received 11 March 2011

Received in revised form 16 November 2011

Accepted 17 November 2011

Available online 17 December 2011

\section{Keywords:}

Biodiversity

Birds

Species richness

Habitat structure

Texture

Multiple linear regression

Landsat

NLCD

\begin{abstract}
A B S T R A C T
Avian biodiversity is threatened, and in order to prioritize limited conservation resources and conduct effective conservation planning a better understanding of avian species richness patterns is needed. The use of image texture measures, as a proxy for the spatial structure of land cover and vegetation, has proven useful in explaining patterns of avian abundance and species richness. However, prior studies that modeled habitat with texture measures were conducted over small geographical extents and typically focused on a single habitat type. Our goal was to evaluate the performance of texture measures over broad spatial extents and across multiple habitat types with varying levels of vertical habitat structure. We calculated a suite of texture measures from 114 Landsat images over a study area of $1,498,000 \mathrm{~km}^{2}$ in the Midwestern United States, which included habitats ranging from grassland to forest. Avian species richness was modeled for several functional guilds as a function of image texture. We subsequently compared the explanatory power of texture-only models with models fitted using landscape composition metrics derived from the National Land Cover Dataset, as well as models fitted using both texture and composition metrics. Measures of image texture were effective in modeling spatial patterns of avian species richness in multiple habitat types, explaining up to $51 \%$ of the variability in species richness of permanent resident birds. In comparison, landscape composition metrics explained up to 56\% of the variability in permanent resident species richness. In the most heavily forested ecoregion, texture-measures outperformed landscape metrics, and the two types of measurements were complementary in multivariate models. However, in two out of three ecoregions examined, landscape composition metrics consistently performed slightly better than texture measures, and the variance explained by the two types of measures overlapped considerably. These results show that image texture measures derived from satellite imagery can be an important tool for modeling patterns of avian species richness at broad spatial extents, and thus assist in conservation planning. However, texture measures were slightly inferior to landscape composition metrics in about three-fourths of our models. Therefore texture measures are best considered in conjunction with landscape metrics (if available) and are best used when they show explanatory ability that is complementarity to landscape metrics.
\end{abstract}

(c) 2011 Elsevier Inc. All rights reserved.

\section{Introduction}

Avian biodiversity is under severe threat from human-caused habitat loss and fragmentation (Gaston et al., 2003). The identification of high-value habitat is critical for maintaining avian biodiversity, given that the resources available for habitat conservation are limited (Turner et al., 2003). While some broad-scale mapping of biodiversity has been conducted (Buckton \& Ormerod, 2002; Myers et al., 2000),

\footnotetext{
* Corresponding author at: Department of Forest and Wildlife Ecology, 226 Russell Labs 1630 Linden Drive, Madison, WI 53706, USA. Tel.: +1 608265 9219; fax: +1 608262 9922.
}

E-mail address: pdculbert@wisc.edu (P.D. Culbert). the spatial resolution of these maps is often too coarse to be directly relevant to resource managers and land use planners. Therefore, alternative approaches that can provide maps of avian species richness at a finer spatial resolution are needed for land management and biogeography alike. However, surveying avian species richness exhaustively is not feasible, and it is not clear which approaches can best explain and predict broad-scale avian species richness patterns while retaining a high level of detail.

Modeling and mapping of broad-scale patterns of biodiversity greatly benefits from the use of remotely sensed data (Kerr \& Ostrovsky, 2003). A major advantage of remotely sensed data over field data is the availability of high spatial and temporal resolution data over very broad extents (Innes \& Koch, 1998; Roy, 2003). Remote sensing-based 
approaches have played a major role in many recent studies attempting to understand and map patterns of biodiversity (Nagendra, 2001; Turner et al., 2003). Remote sensing approaches fall into three main categories: (1) direct mapping of individuals or assemblages of individuals, (2) indirect mapping based on inference derived from models based on habitat maps (such as landcover classifications) and observed species distribution patterns, or (3) indirect mapping based on relationships between spectral radiance information obtained from unclassified imagery and species distribution (Nagendra, 2001).

In order to infer biodiversity patterns from remotely sensed data, it is important to understand which environmental factors drive biodiversity. Three of the hypothesized primary drivers of biodiversity are climatic stability, productivity, and habitat structure (MacArthur, 1972). Of these three, remotely-sensed measures of climate and productivity are standardized and freely available over broad spatial extents such as PRISM (Daly et al., 2008) temperature and precipitation data, MODIS land surface temperature data (Wan et al., 2002), AVHRR NDVI and MODIS leaf area index data (Myneni et al., 2002, 1997), vegetation indices (Huete et al., 2002), and net primary productivity (Turner et al., 2006). In contrast, there are no standardized measures of habitat structure for broad extents. For the purpose of our study, we define habitat structure as both the vertical structure of vegetation (such as the vertical configuration of vegetation layers in a forest) as well as horizontal vegetation structure (such as the existence of canopy gaps in a forest).

Habitat structure influences biodiversity, particularly in birds (Clawges et al., 2008; Luoto et al., 2004; MacArthur \& MacArthur, 1961; MacArthur et al., 1966; Tews et al., 2004; Wiens, 1974; Willson, 1974), as greater variety in habitat leads to greater variety in species (Rosenzweig, 1995; Tews et al., 2004). Birds can finely partition foraging areas (MacArthur, 1958). Thus, more structure may support a higher number of foraging niches or support a larger food supply (such as insects) allowing for more species (Cody, 1981).

Direct field measurements of habitat structure, while effective in explaining avian distribution patterns, are time consuming and impractical to conduct at a state-wide or regional scale (Bergen et al., 2009), which are the very scales at which conservation planning and land management is conducted. LiDAR (light detection and ranging) technology has proven very effective at remotely measuring vegetation structure, especially in relation to patterns of avian abundance and biodiversity (Bergen et al., 2009; Clawges et al., 2008; Goetz et al., 2007; Lesak et al., 2011; Seavy et al., 2009). Unfortunately, operational LiDAR sensors have only recently become widespread, and most areas of the United States have not been imaged by LiDAR, or areas have been imaged by different types of sensors, complicating analyses. Therefore, broad-scale studies involving measurement of habitat structure by LiDAR remain impractical.

Landscape metrics derived from land cover classifications can also serve as habitat structure measures when explaining biodiversity patterns (Atauri and De Lucio, 2001; Donovan and Flather, 2002; Farina, 1997; Kondo and Nakagoshi, 2002). However, metrics are based on land cover classifications, which remove within-class heterogeneity. One promising alternative for characterizing habitat structure using remotely sensed data are image texture measures derived from remotely sensed imagery. Texture measures can capture both between-habitat and within-habitat structures, providing a potential advantage over landscape metrics.

Remotely sensed images are composed of both tone (spectral variation) and texture (spatial variation) (Baraldi \& Parmiggiani, 1995; Haralick, 1979). Texture measures quantify spatial heterogeneity which is valuable for both land cover classification (Coburn \& Roberts, 2004; Franklin et al., 2000, 2001) and habitat modeling (Estes et al., 2008; Hepinstall \& Sader, 1997; Tuttle et al., 2006). One of the most promising applications of texture measures is the characterization of habitat structure, such as forest structure (Kayitakire et al., 2006; Wunderle et al., 2007), woody plant encroachment of savanna (Hudak \& Wessman, 1998), and leaf area index (Wulder et al., 1998).

The most commonly used measures of texture are divided into two groups: first-order (occurrence) and second-order (co-occurrence) (Haralick et al., 1973). First-order measures are summary statistics, such as mean and standard deviation, calculated from the spectral values of pixels in a defined neighborhood, typically implemented as a moving window. Second-order texture measures take into account the spatial distribution and dependencies of spectral values (Coburn \& Roberts, 2004). Second-order measures are derived from a gray-level co-occurrence matrix (GLCM) (Haralick et al., 1973). The GLCM is a symmetric $n$-by-n matrix, where $n$ is the number of possible graytone values. Entries $\mathrm{P}_{\mathrm{ij}}$ in the matrix, represent the relative frequency of pixels with tone levels $\mathrm{i}$ and $\mathrm{j}$ co-occurring adjacent to one another (Haralick et al., 1973). The GLCM is also calculated for a neighborhood, typically a moving window. Haralick, Shanmuga, and Dinstein (1973) originally proposed 14 texture measures derived from the GLCM. Many of these original second-order measures have been found to be highly correlated, and a subset of six measures is considered most useful for remote sensing analysis: angular second moment (ASM), contrast, correlation, homogeneity, variance, and entropy, with the first three being the least correlated (Baraldi \& Parmiggiani, 1995; Kayitakire et al., 2006).

Broadly speaking, most second-order texture measures either measure homogeneity or heterogeneity in the digital numbers (DNs) of pixels within a specified neighborhood (Baraldi \& Parmiggiani, 1995; Haralick et al., 1973). Measures of homogeneity include homogeneity and angular second moment. Homogeneity is high when adjacent pixels have similar reflectance DNs. Angular second moment measures "uniformity" meaning that certain pairs of DN values occur adjacent to one another in the image very frequently. An image where all pixels have the same DN would have high uniformity, but so would a regular checkerboard image as the white-black adjacency would occur very frequently. Measures of heterogeneity include entropy, contrast, and variance. Entropy measures disorder. The highest entropy values occur when the GLCM is uniform, indicating a perfectly random arrangement of DNs in the original image. Contrast has high values when adjacent pixels have a very large difference in DNs. Variance measures the amount of variability in the GLCM, and is very highly correlated with first-order variance. Correlation measures the correlation in DN of pixel pairs. For this reason, either a very homogenous image or a very heterogenous image could exhibit strong correlation.

The properties of different texture measures explain how they relate to what is visible in a satellite image. A given landcover class, e.g., a deciduous forest, will exhibit homogeneity if adjacent pixels have similar reflectance values. A more heterogeneous forest may include tree species with different spectral properties, or canopy gaps resulting in shadows which will tend to have different reflectance values and texture measures capturing heterogeneity will be higher. Textural features of course also depend on heterogeneity and homogeneity among landcover classes. For example, a patchwork of agricultural fields planted to different crops or at different stages (e.g., bare soil versus mature crop) would have high within-field homogeneity, but high between-field heterogeneity. Similarly, sharp transitions among different land cover classes, such as between forest and pasture, will increase measures of heterogeneity, such as sum of squares variance or contrast.

Given that image texture measures can characterize habitat structure (Franklin et al., 2001; Kayitakire et al., 2006), texture measures have been used successfully to map habitat of species as varied as the mountain bongo (an endangered antelope species) (Estes et al., 2008, 2010), the redtail monkey (Stickler \& Southworth, 2008), and avian communities. In Maine, for example, texture measures derived from remotely sensed imagery proved useful in bird presence/absence models (Hepinstall \& Sader, 1997). In Argentina, texture measures captured meaningful variation within grasslands, improving habitat suitability models for the Greater Rhea (Bellis et al., 2008). In a desert 
scrub ecosystem of the Chihuahuan Desert of New Mexico, texture measures derived from Landsat imagery and 1-m resolution digital aerial photographs explained patterns of avian species richness well (StLouis et al., 2009, 2006). Similarly, texture measures derived 0.5-m resolution photographs were successful in explaining avian species richness in prairies and savannas in western Wisconsin (Wood et al., 2007).

These studies show the promise of texture measures for mapping patterns of biodiversity but also present questions for further research. The ecosystems where most of these studies took place (i.e., Grassland, desert scrub, and prairie savanna) have little vertical structure. The ability to characterize the lower strata of structurally complex, closed-canopy habitats, such as forests, is a potential limitation of texture measures derived from passive remote sensing imagery (Estes et al., 2008; Gottschalk et al., 2005). Furthermore, most of the studies investigating the use of image texture for biodiversity modeling were conducted at relatively small spatial extents $\left(4782 \mathrm{~km}^{2}\right.$, Bellis et al., 2008; $250 \mathrm{~km}^{2}$, Wood et al., 2007; $2800 \mathrm{~km}^{2}$, St-Louis et al., 2009, 2006). A study modeling avian species occurrence over a much larger study area, i.e., the state of Maine $\left(91,600 \mathrm{~km}^{2}\right)$ (Hepinstall \& Sader, 1997), showed that texture was effective, but considered only first-order texture measures. Thus, it remains unclear whether image texture is equally useful in explaining avian species richness at broader spatial extents and in areas with more vertically complex habitat structure, such as forests.

Our overall goal was to evaluate the ability of satellite image texture measures to explain avian species richness. We were specifically interested in understanding: 1) whether measures of image texture can explain patterns of avian species richness across broad regions that include vertically complex habitats such as forests, and 2) if measures of image texture compare favorably with landscape composition metrics derived from land cover classifications, such as the proportion of specific land cover classes, for modeling patterns of avian species richness.

Our predictions were that:

1. The ability of image texture to explain patterns of species richness over small extents will scale-up to broad extents.

2. Measures of image texture will better explain patterns of avian species richness in habitats with simple vertical structure, such as grasslands, than in habitats with complex vertical structure, such as forests.

3. Measures of image texture will better explain avian species richness patterns than landscape composition metrics, because landscape metrics ignore within-habitat variability while texture measures capture both between-habitat and within-habitat variability. However, these two groups of measures will be complementary in multivariate models.

4. Because texture measures are associated with landcover and vegetation, which relate to habitat type, they will hold higher explanatory power for habitat-based avian guilds than migratory guilds.

\section{Methods}

\subsection{Study area}

Our study area encompassed three ecoregions at the province level (hereafter ecoregions) totaling $1,498,000 \mathrm{~km}^{2}$ of the Midwestern United States: ecoregion 251 (Prairie Parkland, Temperate) and most of ecoregions 212 (Laurentian Mixed Forest) and 222 (Eastern Broadleaf Forest, Continental) (Bailey, 1995) (Fig. 1). The Prairie Parkland ecoregion was historically composed of prairie alternating with deciduous trees. Today, it is dominated by agriculture, with remnant patches of prairie and small groves and strips of deciduous forest. The Eastern Broadleaf Forest ecoregion is composed primarily of deciduous broadleaf forests, mixed with agriculture. We included the portion of this ecoregion from approximately the state of Michigan and westward. (It should be noted that the Eastern Broadleaf Forest included roughly half of our data points, thereby weighting our fullstudy-area analysis to this ecoregion.) The Laurentian Mixed Forest is in the transition area between broadleaf deciduous forest zones and the boreal forest. The ecoregion is composed of pure stands of deciduous trees, pure stands of conifers, and mixed stands. We included the areas of this ecoregion in Minnesota, Wisconsin, and Michigan, while excluding areas east of Michigan in order to maintain a contiguous study area.

In order to quantify differences in landcover composition (and inferred vertical habitat structure) between ecoregions, we calculated the proportion of forest, agriculture, grassland, and shrubland surrounding the Breeding Bird Survey routes included in our analysis (Table 1). The Laurentian Mixed forest was dominated by forest, indicating the highest level of vertical habitat structure. The Eastern Broadleaf Forest was heavily in agriculture, but with a significant component in forest. The Prairie Parkland was clearly agriculturedominated, reflecting the lowest level of vertical habitat structure.

\subsection{Bird data}

We calculated species richness (our measure of biodiversity) from the North American Breeding Bird Survey (BBS), an annual survey of approximately 3000 routes across the U.S. (Fig. 1). A typical BBS survey consists of recording all birds observed or heard at 50 regularly spaced 3-min point counts along a 39.4-km route (USGS Patuxent Wildlife Research Center 2008). We centered our analysis on the year 2000, calculating the mean species richness of each BBS route from 1998 to 2002 . We included only BBS routes that fall entirely within one of the three ecoregions of study. The BBS data were preprocessed to remove route-years collected by first year observers, or those carried out in suboptimal weather (e.g., high wind or rain). A total of 586 BBS routes fulfilled our criteria, including 161 in Prairie Parkland, 113 in Laurentian Mixed Forest, and 312 in Eastern Broadleaf Forest. Because we did not expect all bird species to respond uniformly to measures of textures, we calculated overall species richness as well as richness within three migratory guilds: permanent residents, short-distance migrants (i.e., species that spend the nonbreeding season primarily in the southern portion of the U.S.), and Neotropical migrants (Peterjohn \& Sauer, 1999; Pidgeon et al., 2007; Rappole, 1995). We also calculated species richness of avian guilds organized by the structural form of habitat they are commonly associated with: forest, shrubland, and grassland (Peterjohn \& Sauer, 1999; Pidgeon et al., 2007).

To adjust for detection probability bias (i.e., the problem that not all bird species are uniformly detectable at a given site), it is recommended that a correction be applied to raw count data to adjust the species richness estimate (Kéry \& Schmid, 2004). We used the software program COMDYN (Hines et al., 1999) to adjust our species richness estimates. COMDYN considers the raw BBS route richness data from a capture-recapture model perspective and uses a jackknife estimator to calculate estimated species richness (Nichols et al., 1998).

\subsection{Image texture data}

We acquired 114 Landsat TM/ETM + scenes (Fig. 2A) from the LEDAPS database (Masek et al., 2006), a collection of atmospherically corrected Landsat images based on the GeoCover dataset (Tucker et al., 2004). We selected scenes from approximately the year 2000, to temporally coincide with our species richness data. All images were acquired during the growing season, however due to the extent of study, it was not possible to obtain all images for the same phenological stage. Therefore, some extraneous phenological variability in the texture measures was likely present (Culbert et al., 2009). For each image, a suite of first- and second-order texture measures were 


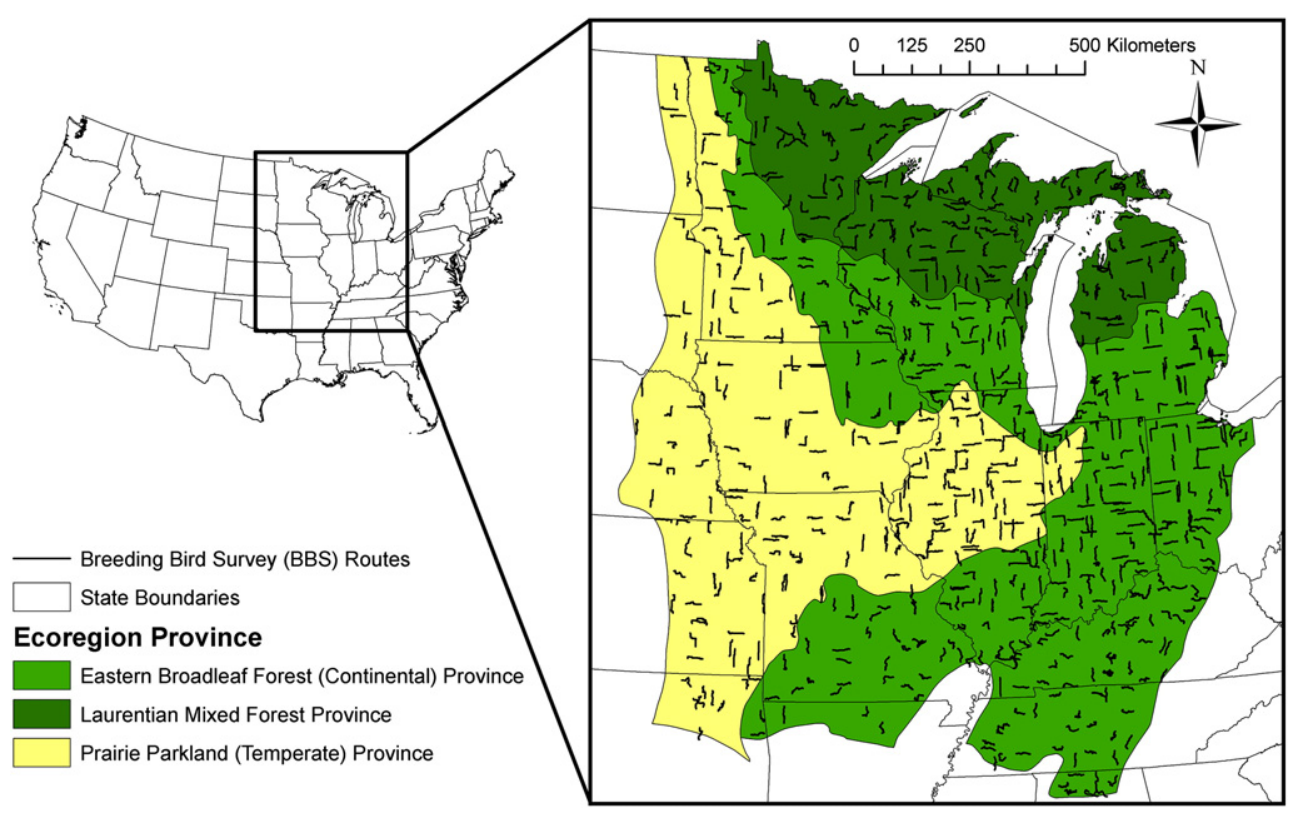

Fig. 1. Study area, including ecoregion boundaries and Breeding Bird Survey (BBS) routes.

calculated using Matlab® R2010a (The MathWorks, 1984-2010), with scripts adapted from St-Louis et al. (2006) (Table 2). First-order mean and standard deviation were calculated for TM bands 1, 2, 3, 4, 5, and 7 , with $5 \times 5$ and $21 \times 21$ moving windows. We also calculated secondorder angular second moment (ASM), contrast, correlation, entropy, homogeneity (Fig. 2B), and sum of squares variance (SSVar). Among all second-order texture measures, these six are considered the most useful for remote sensing analyses, and angular second moment, contrast, and correlation are the three least correlated measures (Baraldi \& Parmiggiani, 1995; Kayitakire et al., 2006). We expected this set of texture measures would adequately characterize vegetation structure and therefore be an appropriate set with which to relate avian species richness. We quantized the imagery to 64 values to limit the size of the GLCM and avoid matrices that are too sparsely populated to provide robust results. To determine minimum and maximum values for the quantization, we calculated the 2.5th and 97.5th percentiles for each band of each image. We then calculated the 2.5th and 97.5th percentile of these values for each band across all images, and we used these values as our minimum and maximum digital numbers (DNs) for the quantization. Second-order textures were calculated using an omnidirectional GLCM (calculated as the mean of the four possible directional GLCMs). Preliminary analysis found strong correlation between texture measures derived from $5 \times 5$ and $21 \times 21$ window sizes, so due

Table 1

Landcover composition of BBS route buffers by ecoregion.

\begin{tabular}{lcccc}
\hline Ecoregion & $\begin{array}{l}\text { Laurentian } \\
\text { mixed } \\
\text { forest }\end{array}$ & $\begin{array}{l}\text { Eastern broadleaf } \\
\text { forest } \\
\text { (continental) }\end{array}$ & $\begin{array}{l}\text { Prairie } \\
\text { parkland } \\
\text { (temperate) }\end{array}$ & $\begin{array}{l}\text { All 3 } \\
\text { ecoregions } \\
\text { combined }\end{array}$ \\
\hline $\begin{array}{c}\text { Proportion } \\
\text { forest } \\
\text { Proportion } \\
\text { agriculture }\end{array}$ & 0.47 & 0.29 & 0.11 & 0.27 \\
$\begin{array}{c}\text { Proportion } \\
\text { grassland }\end{array}$ & 0.17 & 0.52 & 0.69 & 0.50 \\
$\begin{array}{c}\text { Proportion } \\
\text { shrubland }\end{array}$ & 0.01 & 0.01 & 0.08 & 0.04 \\
$\begin{array}{c}\text { Number of BBS } \\
\text { buffers }\end{array}$ & 113 & 312 & 0.00 & 0.01 \\
\hline
\end{tabular}

to the substantial computational requirements, second-order texture measures were calculated only with a $5 \times 5$ window and only for TM bands $2,3,4$, and 5 . Bands 1 and 7 were excluded because we expected band 1 results to be highly correlated with band 2 , and band 7 was less useful than other bands in prior exploratory analysis. This resulted in a total of 48 texture measures (24 first-order and 24 second-order) (Table 1).

In order to relate our texture measures to individual BBS routes, we derived $19.7 \mathrm{~km}$-radius (one-half the length of a BBS route) circular buffers around the centroid of each BBS route (Albright et al., 2010, 2011; Flather \& Sauer, 1996; Rittenhouse et al., 2010). We chose this radius because it encompasses the entire BBS route, regardless of varying route path, thus resulting in a uniform area and shape for each route. Furthermore, this distance is comparable to the median maximum natal dispersal distance $(31 \mathrm{~km})$ of 76 avian species (Sutherland et al., 2000) estimated from body size relationships, and is consistent with the recommendation that landscape effects on songbirds should be examined over tens of kilometers to capture dispersal effects (Tittler et al., 2009). For each BBS route, we calculated the within-buffer mean and standard deviation of each of the 48 texture measures, yielding 96 explanatory variables total. We calculated buffer summary statistics from a single Landsat scene whenever possible. Of the 586 BBS route buffers, 164 did not fall entirely within a single Landsat footprint. In those cases, the buffer summary statistics were calculated from mosaics of adjacent Landsat scenes.

\subsection{Land cover data}

We derived landscape composition metrics for each BBS route for comparison with our texture results. Landscape metrics were calculated from the 2001 National Land-Cover Database (NLCD) (Homer et al., 2004). Within each BBS route buffer, the relative abundance was calculated for 13 land-cover classes: developed (NLCD 2001 classes $21,22,23$, and 24), barren (31), deciduous forest (41), evergreen forest (42), mixed forest (43), shrub-scrub (52), grassland (71), pasture (81), cultivated crops (82), woody wetland (90), and herbaceous wetland (95). Additionally, the total number of landcover classes present and the Shannon diversity index (Shannon, 1948) of class distribution were calculated for each buffer. 

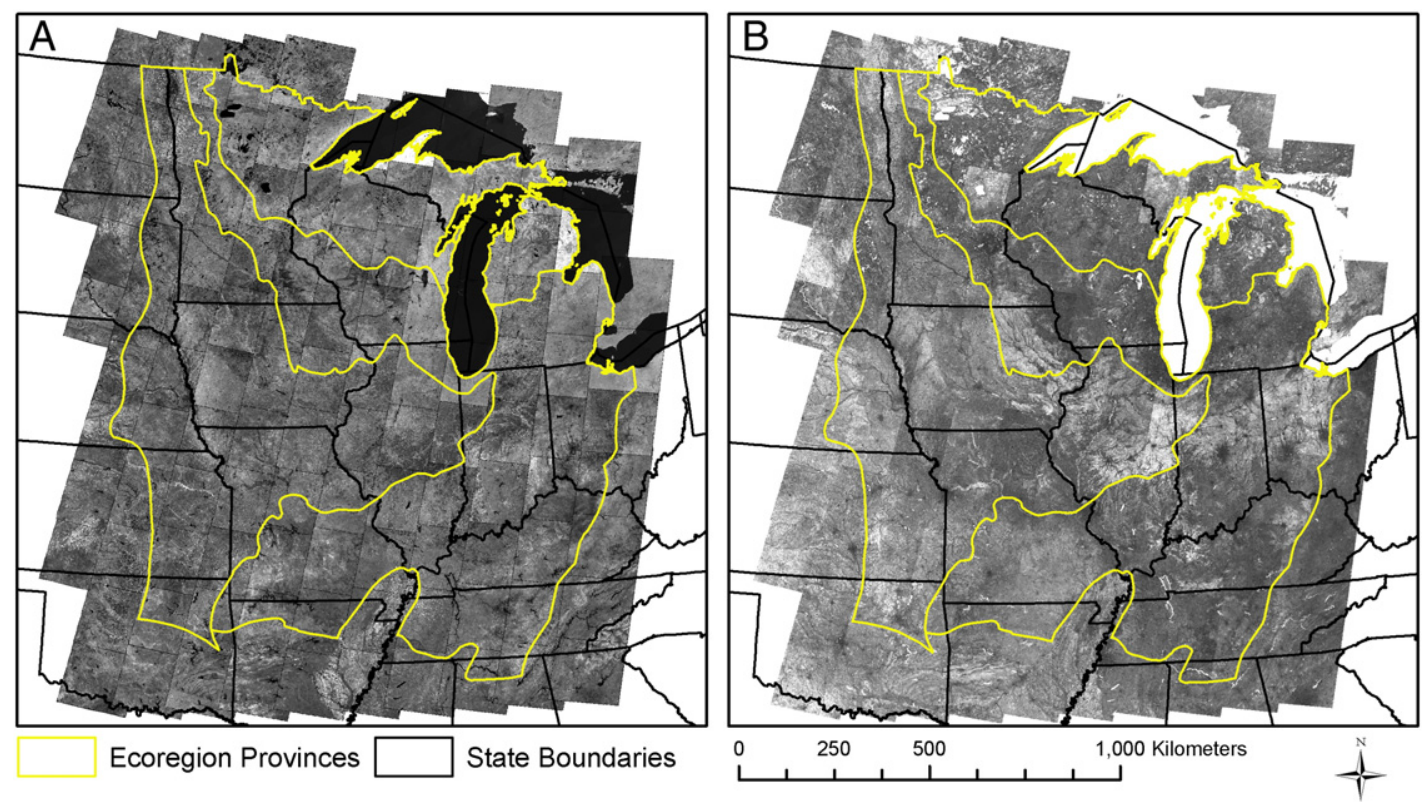

Fig. 2. (A) Landsat (band 4) data for the study area. (B) Second-order homogeneity of band 4.

\subsection{Statistical analysis}

The Landsat image texture processing generated 96 potential explanatory variables. Given our sample sizes $(161,113,312$, and 586), this was an unreasonably large pool of explanatory variables. Furthermore, many texture measures are correlated (Baraldi \& Parmiggiani, 1995) and we also expected there would be correlation between some of the bands, window sizes, and summary statistics (mean or standard deviation). We therefore analyzed the correlation in this variable pool in order to exclude collinear variables $(|r|>0.8)$ and reduce the number of variables. Additionally, we created a univariate linear model for each combination of texture measure variable (96) and avian guild (7) for a total of 672 models. We ranked the individual texture variables based on their $\mathrm{R}^{2}$ value for the "all birds" guild (results not shown). Rankings of texture measure variables based on performance for other guilds were similar. Correlation analysis first focused on within-texture measure correlation. For each texture measure (mean, standard deviation, angular second moment, contrast, correlation, entropy, homogeneity, and sum of squares variance), correlations between bands, window sizes, or summary statistics were analyzed. For variable pairs with $|r|>0.8$, the variable with the lower univariate $\mathrm{R}^{2}$ ranking was dropped. After within-texture correlations were accounted for, the remaining between-texture correlations were then eliminated by dropping the variable with the poorer univariate $\mathrm{R}^{2}$ rank.

Table 2

Combinations of texture, window size, and Landsat TM band that were calculated for the study area.

\begin{tabular}{llll}
\hline Order & Texture & Window size(s) & TM bands \\
\hline 1st & Mean & $5 \times 5,21 \times 21$ & $1,2,3,4,5,7$ \\
1st & Standard deviation & $5 \times 5,21 \times 21$ & $1,2,3,4,5,7$ \\
2nd & Angular second moment (ASM) & $5 \times 5$ & $2,3,4,5$ \\
2nd & Contrast & $5 \times 5$ & $2,3,4,5$ \\
2nd & Correlation & $5 \times 5$ & $2,3,4,5$ \\
2nd & Entropy & $5 \times 5$ & $2,3,4,5$ \\
2nd & Homogeneity & $5 \times 5$ & $2,3,4,5$ \\
2nd & Sum of squares variance (SSVar) & $5 \times 5$ & $2,3,4,5$ \\
\hline
\end{tabular}

The relationships between texture measures and avian species richness were explored using multiple linear regression models. Model selection was implemented with the step function in $\mathrm{R}(\mathrm{R}$ Development Core Team, 2009). For each guild, a candidate model was selected using forward selection, backward selection, and bidirectional selection starting from both the full and null models. Of the four candidate models produced by stepwise selection, we selected the model with the lowest Akaike's information criterion (AIC) value as our best model. This analysis was carried out for the entire study area, as well as for each ecoregion separately.

In addition to the texture-based models, we modeled avian species richness as a function of landscape composition metrics only, in order to have a benchmark with which to compare the performance of

Table 3

Texture variables calculated from Landsat imagery. Based on correlation analysis, 74 variables (marked “-”) were excluded from subsequent analysis, and 22 variables (marked "X") were retained.

\begin{tabular}{|c|c|c|c|c|c|c|}
\hline \multirow[t]{2}{*}{ Texture } & \multicolumn{6}{|c|}{ Landsat TM band } \\
\hline & 1 & 2 & 3 & 4 & 5 & 7 \\
\hline Mean_5×5_Mean & - & - & - & - & - & - \\
\hline Mean_21×21_Mean & - & $\mathrm{X}$ & - & $\mathrm{X}$ & - & - \\
\hline Mean_5 $\times 5$ _SD & $\mathrm{X}$ & - & - & $\mathrm{X}$ & - & $\mathrm{X}$ \\
\hline Mean_21×21_SD & $\mathrm{X}$ & - & - & $\mathrm{X}$ & - & $\mathrm{X}$ \\
\hline SD_5 $\times 5 \_$Mean & - & - & - & - & - & - \\
\hline SD_21 $\times 21$ Mean & - & - & - & - & - & - \\
\hline SD_5 $\times 5 \_S D$ & $\mathrm{X}$ & - & - & $\mathrm{X}$ & $\mathrm{X}$ & - \\
\hline SD_21×21_SD & - & - & - & - & - & - \\
\hline ASM_5×5_Mean & & - & - & - & - & \\
\hline ASM_5 $\times 5 \_S D$ & & $\mathrm{X}$ & - & - & - & \\
\hline Contrast_5×5_Mean & & - & - & - & - & \\
\hline Contrast_5 $\times 5$ SD & & - & - & - & - & \\
\hline Correlation_5 $\times 5$ _Mean & & - & $\mathrm{X}$ & $\mathrm{X}$ & $\mathrm{X}$ & \\
\hline Correlation_5 $\times 5$ _SD & & $\mathrm{X}$ & - & - & $\mathrm{X}$ & \\
\hline Entropy_5×5_Mean & & - & - & - & - & \\
\hline Entropy_5 $\times 5$ _SD & & - & - & - & - & \\
\hline Homogeneity_5×5_Mean & & - & - & $\mathrm{X}$ & $\mathrm{X}$ & \\
\hline Homogeneity_5 $\times 5$ _SD & & $\mathrm{X}$ & - & $\mathrm{X}$ & - & \\
\hline SSVariance_5 $5 \times 5$ _mean & & - & $\mathrm{X}$ & - & - & \\
\hline SSVariance_5×5_SD & & - & - & - & - & \\
\hline
\end{tabular}


Table 4

Final guild species richness models as determined by stepwise selection using AIC.

\begin{tabular}{|c|c|c|c|c|c|c|c|c|c|c|c|c|c|c|c|c|c|c|c|c|c|c|c|c|c|c|}
\hline \multirow{2}{*}{$\begin{array}{l}\text { Texture measure } \\
\text { Mean_21×21_B2_Mean }\end{array}$} & \multicolumn{2}{|l|}{ All birds } & \multicolumn{4}{|c|}{ Forest birds } & \multicolumn{4}{|c|}{ Grassland birds } & \multicolumn{4}{|c|}{$\begin{array}{l}\text { Shrubland } \\
\text { birds }\end{array}$} & \multicolumn{4}{|c|}{$\begin{array}{l}\text { Neotropical } \\
\text { migrants }\end{array}$} & \multicolumn{4}{|c|}{$\begin{array}{l}\text { Permanent } \\
\text { residents }\end{array}$} & \multicolumn{4}{|c|}{$\begin{array}{l}\text { Short-distance } \\
\text { migrants }\end{array}$} \\
\hline & A & $E$ & $\mathrm{~A}$ & & $\mathrm{E}$ & & & $\mathrm{L}$ & & $\mathrm{P}$ & $\mathrm{A}$ & & & & A & & $E$ & $\mathrm{P}$ & A & & $E$ & & & & & \\
\hline Mean_21×21_B4_Mean & $\mathrm{L}$ & & $\mathrm{A}$ & L & & & A & & & & A & & $\mathrm{E}$ & & & L & & & A & $\mathrm{L}$ & $E$ & & & & $\mathrm{E}$ & \\
\hline Mean_5×5_B1_SD & & & & & $\mathrm{E}$ & & & & & & A & & & & & & $\mathrm{E}$ & & A & & & & & L & & \\
\hline Mean_5×5_B4_SD & & & & & & & $\mathrm{A}$ & & $\mathrm{E}$ & & & L & & $\mathrm{P}$ & & & $E$ & $\mathrm{P}$ & A & & $\mathrm{E}$ & $\mathrm{P}$ & & & $\mathrm{E}$ & $\mathrm{P}$ \\
\hline Mean_5×5_B7_SD & L & $\mathrm{P}$ & & & & $\mathrm{P}$ & $\mathrm{A}$ & & $\mathrm{E}$ & $\mathrm{P}$ & $\mathrm{A}$ & L & $\mathrm{E}$ & & & & & $\mathrm{P}$ & A & & $\mathrm{E}$ & $\mathrm{P}$ & A & L & & \\
\hline Mean_21×21_B1_SD & A & & $\mathrm{A}$ & & & & & & & & & & & & A & & $\mathrm{E}$ & & & & & $\mathrm{P}$ & & & & \\
\hline Mean_21×21_B4_SD & $\mathrm{A}$ & E & $\mathrm{A}$ & & $\mathrm{E}$ & & A & $\mathrm{L}$ & $\mathrm{E}$ & & & & & $\mathrm{P}$ & A & & $\mathrm{E}$ & $\mathrm{P}$ & A & $\mathrm{L}$ & $E$ & $\mathrm{P}$ & $\mathrm{A}$ & & & \\
\hline Mean_21×21_B7_SD & $\mathrm{L}$ & & $\mathrm{A}$ & L & & & A & $\mathrm{L}$ & $E$ & $\mathrm{P}$ & $\mathrm{A}$ & $\mathrm{L}$ & $E$ & $\mathrm{P}$ & & L & & & A & & $E$ & & $\mathrm{~A}$ & $\mathrm{~L}$ & & $\mathrm{P}$ \\
\hline SD_5 $\times 5$ 51_SD & A & $E$ & $\mathrm{~A}$ & & $\mathrm{E}$ & & & & $\mathrm{E}$ & $\mathrm{P}$ & & & & & A & & $\mathrm{E}$ & $\mathrm{P}$ & & $\mathrm{L}$ & & & & & & \\
\hline SD_5 ×5_B4_SD & L & $\mathrm{E}$ & & L & & & A & & $\mathrm{E}$ & & & & $\mathrm{E}$ & $\mathrm{P}$ & & L & $\mathrm{E}$ & $\mathrm{P}$ & A & & $\mathrm{E}$ & $\mathrm{P}$ & & & & \\
\hline SD_5 $\times 5$ B 5 _SD & $\mathrm{A}$ & & & & & & A & $\mathrm{L}$ & $\mathrm{E}$ & & & & $E$ & & A & & & & A & & $E$ & $\mathrm{P}$ & A & & & \\
\hline ASM_5 $\times 5$ 5_B2_SD & & & & & & & & & & & & & & $\mathrm{P}$ & & & & $\mathrm{P}$ & & & & & & & $\mathrm{E}$ & $\mathrm{P}$ \\
\hline Corr_5 $\times 5$ 533_Mean & A & & $A$ & & & & A & & & $\mathrm{P}$ & & & $\mathrm{E}$ & $\mathrm{P}$ & A & & & & A & & & $\mathrm{P}$ & & & & \\
\hline Corr_5 $\times 5$ _B4_Mean & $L$ & & & & & & & $\mathrm{~L}$ & $\mathrm{E}$ & & A & $\mathrm{L}$ & $\mathrm{E}$ & $\mathrm{P}$ & & L & & & A & & $\mathrm{E}$ & $\mathrm{P}$ & & $\mathrm{L}$ & & \\
\hline Corr_5 $\times 5$ 5_B5_Mean & L & $\mathrm{E}$ & & & & $\mathrm{P}$ & A & & & $\mathrm{P}$ & & $\mathrm{L}$ & & $\mathrm{P}$ & & $\mathrm{L}$ & & & & & $\mathrm{E}$ & $\mathrm{P}$ & & $\mathrm{L}$ & & \\
\hline Corr_5×5_B2_SD & A & $\mathrm{P}$ & A & & $\mathrm{E}$ & $\mathrm{P}$ & & L & & & A & & $\mathrm{E}$ & $\mathrm{P}$ & A & & $\mathrm{E}$ & $\mathrm{P}$ & A & & $\mathrm{E}$ & $\mathrm{P}$ & A & & $\mathrm{E}$ & $\mathrm{P}$ \\
\hline Corr_5×5_B5_SD & A & $\mathrm{E}$ & A & & $\mathrm{E}$ & & & & $\mathrm{E}$ & & A & & $\mathrm{E}$ & & & & $\mathrm{E}$ & & A & & $\mathrm{E}$ & & A & & E & \\
\hline Homog_5×5_B4_Mean & $\mathrm{L}$ & & & $L$ & $E$ & & & L & & $\mathrm{P}$ & & $\mathrm{L}$ & & & & L & $\mathrm{E}$ & & A & $\mathrm{L}$ & & & A & $\mathrm{L}$ & & $\mathrm{P}$ \\
\hline Homog_5×5_B5_Mean & A & $\mathrm{P}$ & A & & $\mathrm{E}$ & $P$ & A & & & & A & & & $\mathrm{P}$ & A & & & & & & & $\mathrm{P}$ & A & & & \\
\hline Homog_5×5_B2_SD & L & & & L & & & & & & & $\mathrm{A}$ & L & E & $\mathrm{P}$ & & L & & $\mathrm{P}$ & & $\mathrm{L}$ & E & & & $\mathrm{L}$ & & $\mathrm{P}$ \\
\hline Homog_5×5_B4_SD & & $\mathrm{E}$ & & & & & & & & & $\mathrm{P}$ & & & & & & & & & & & & & & & $\mathrm{P}$ \\
\hline SSVar_5 $\times 5$ _B3_Mean & & & & & & & & & & $\mathrm{E}$ & & & $\mathrm{L}$ & $\mathrm{E}$ & $P$ & A & $\mathrm{E}$ & & A & & & $\mathrm{P}$ & & L & $\mathrm{E}$ & $\mathrm{P}$ \\
\hline \multicolumn{27}{|l|}{ Model adjusted $R^{2}$} \\
\hline & \multicolumn{2}{|l|}{$0.29(\mathrm{~A})$} & \multicolumn{4}{|c|}{$0.42(\mathrm{~A})$} & \multicolumn{4}{|c|}{$0.26(\mathrm{~A})$} & \multicolumn{4}{|c|}{$0.28(\mathrm{~A})$} & \multicolumn{4}{|c|}{$0.35(\mathrm{~A})$} & \multicolumn{4}{|c|}{$0.40(\mathrm{~A})$} & \multicolumn{4}{|c|}{$0.07(A)$} \\
\hline & \multicolumn{2}{|l|}{$0.23(\mathrm{~L})$} & \multicolumn{4}{|c|}{$0.25(\mathrm{~L})$} & 0.4 & (L) & & & & (L) & & & & (L) & & & 0.1 & $(\mathrm{~L})$ & & & & (L) & & \\
\hline & $0.29(\mathrm{E})$ & & & (E) & & & 0.3 & (E) & & & & (E) & & & & $(\mathrm{E})$ & & & 0.4 & $(E)$ & & & & (E) & & \\
\hline & $0.19(\mathrm{P})$ & & 0.2 & (P) & & & 0.2 & $(\mathrm{P})$ & & & & (P) & & & & $(\mathrm{P})$ & & & 0.5 & $(\mathrm{P})$ & & & & $(\mathrm{P})$ & & \\
\hline Number of variables/Degrees of freedom & & & & & & & & & & & & & & & & & & & & & & & & $1 / 1$ & & \\
\hline & $9 / 576(A)$ & & & 575( & & & $10 /$ & $75(A$ & & & & 75( & & & & 76(A) & & & & 569( & & & & & & \\
\hline & & & & & & & & & & & & $4(\mathrm{~L}$ & & & & & & & & & & & & $4(\mathrm{~L}$ & & \\
\hline & $9 / 103(\mathrm{~L})$ & & & )7( & & & $7 / 1$ & $5(\mathrm{~L})$ & & & & & & & & $5(\mathrm{~L})$ & & & $5 / 1$ & $\mathrm{D}(\mathrm{L})$ & & & & & & \\
\hline & $8 / 303(\mathrm{E})$ & & & $3(\mathrm{E}$ & & & & & & & & & & & & & & & & & & & & & & \\
\hline & & & & & & & $\begin{array}{l}10 / \\
8 / 1\end{array}$ & 01(B & & & & 00( & & & & 300 (E & & & & 298 & & & & $5(\mathrm{E}$ & & \\
\hline & 4/156(P) & & & $56(P$ & & & & & & & & 48( & & & & $51(\mathrm{P})$ & & & & $148(1$ & & & & & & \\
\hline
\end{tabular}

$\mathrm{A}=$ All three ecoregions together, $\mathrm{L}=$ Laurentian mixed forest, $\mathrm{E}=$ Eastern broadleaf forest (continental), $\mathrm{P}=$ Prairie parkland (temperate).

texture measures. Lastly, we were interested in whether texture measures were complimentary to landscape metrics, so we modeled avian species richness as a function of both texture and landcover metrics.

\section{Results}

Correlation analysis of the 96 texture measure variables showed that 441 (9.7\%) of the 4560 unique combinations of variable pairs exceeded our collinearity threshold $(|r|>0.8)$. Once all correlations greater than our threshold were addressed, 22 texture variables remained (Table 3 ).

Over the full study area, all but the models for short-distance migrant explained at least $26 \%$ of the variability of species richness with an average adjusted $\mathrm{R}^{2}$ value of 0.30 (Table 4). The forest bird and permanent resident models were the best (as determined by $\mathrm{R}^{2}$ ), with adjusted $R^{2}$ values of 0.42 and 0.40 , respectively. Three of the texture measures, standard deviation of $21 \times 21$ band 4 mean, standard deviation of $5 \times 5$ band 2 correlation, and mean of $5 \times 5$ band 5 homogeneity were included in six of the seven models.

Model performance in the Laurentian Mixed Forest showed strong differences compared to the full study area models (Table 4). The average model adjusted $\mathrm{R}^{2}$ was similar, at 0.24 . However, the grassland bird model was the strongest model with an adjusted $\mathrm{R}^{2}$ value of 0.41 , while adjusted $R^{2}$ values for the other six models ranged from 0.16 (permanent residents) to 0.25 (forest birds). The permanent residents model performed the worst in this ecoregion, though it was one of the strongest models for the study area as a whole. The forest bird model also performed more poorly in this ecoregion (adjusted $\mathrm{R}^{2}=0.25$ ) than in the full study area (adjusted $\mathrm{R}^{2}=0.42$ ), even though the Laurentian Mixed Forest ecoregion is the most heavily forested of the three ecoregions in our study area. The three texture measures that were most frequently included in the models were mean of $5 \times 5$ band 4 homogeneity (all seven models), standard deviation of $21 \times 21$ band 7 mean (six models), and standard deviation of $5 \times 5$ band 2 homogeneity (six models).

The Eastern Broadleaf Forest had the models with the highest explanatory power, with an average adjusted $R^{2}$ value of 0.32 and top model $\mathrm{R}^{2}$ values up to 0.46 (permanent residents) and 0.45 (forest birds) (Table 4). Three texture variables were frequently included in models: standard deviation of $5 \times 5$ band 5 correlation (all seven models), standard deviation of $5 \times 5$ band 2 correlation (six models), and standard deviation of $21 \times 21$ band 4 mean (five models).

The Prairie Parkland (Temperate) ecoregion had the strongestperforming single model, with texture measures explaining up to $51 \%$ of the variation in permanent resident species richness (Table 4). The average adjusted $R^{2}$ value of the seven models was 0.27 . The standard deviation of $5 \times 5$ band 2 correlation ( six of seven models), standard deviation of $5 \times 5$ band 7 mean (five models), and mean of $5 \times 5$ band 5 correlation (five models) were frequently included in the best models.

For each ecoregion, and for the study area as a whole, the model selection process was repeated with landscape composition metrics derived from the NLCD as the explanatory variables. Over the entire 
Table 5

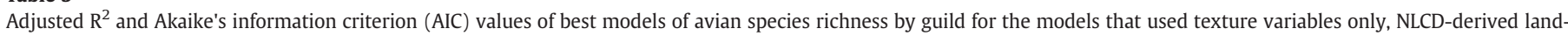

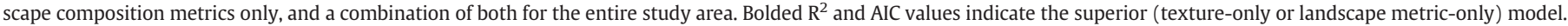

\begin{tabular}{|c|c|c|c|c|c|c|c|c|c|c|c|}
\hline \multirow[t]{2}{*}{ Guild } & \multicolumn{3}{|c|}{$\begin{array}{l}\text { Texture-only } \\
\text { models }\end{array}$} & \multicolumn{3}{|c|}{$\begin{array}{l}\text { Landscape metric-only } \\
\text { models }\end{array}$} & \multicolumn{3}{|c|}{$\begin{array}{l}\text { Texture and landscape metric } \\
\text { models }\end{array}$} & \multirow[b]{2}{*}{ Abs. $\mathrm{R}^{2}$ gain } & \multirow[b]{2}{*}{ Rel. $R^{2}$ gain } \\
\hline & Adj. $R^{2}$ & AIC & $\overline{\# \text { of vars }}$ & Adj. $\mathrm{R}^{2}$ & AIC & $\overline{\# \text { of vars }}$ & Adj. $\mathrm{R}^{2}$ & AIC & \# of vars & & \\
\hline All birds & 0.29 & 2844.1 & 9 & 0.41 & 2738.0 & 6 & 0.45 & 2710.2 & 21 & 0.039 & $9 \%$ \\
\hline Forest birds & 0.42 & 2683.3 & 10 & 0.51 & 2579.7 & 7 & 0.55 & 2536.5 & 18 & 0.042 & $8 \%$ \\
\hline Grassland birds & 0.26 & 1018.1 & 10 & 0.31 & 971.1 & 8 & 0.39 & 910.4 & 20 & 0.078 & $25 \%$ \\
\hline Shrubland birds & 0.28 & 1001.2 & 10 & 0.31 & 974.0 & 3 & 0.39 & 913.7 & 19 & 0.077 & $25 \%$ \\
\hline Neotropical migrants & 0.35 & 2426.8 & 9 & 0.46 & 2324.9 & 7 & 0.48 & 2311.2 & 24 & 0.025 & $6 \%$ \\
\hline Permanent residents & 0.40 & 1113.3 & 16 & 0.35 & 1158.9 & 8 & 0.46 & 1058.6 & 18 & 0.055 & $14 \%$ \\
\hline Short-distance migrants & 0.07 & 1302.9 & 8 & 0.17 & 1241.6 & 4 & 0.23 & 1203.3 & 20 & 0.070 & $42 \%$ \\
\hline Average & 0.30 & 1770.0 & 10.3 & 0.36 & 1712.6 & 6.1 & 0.42 & 1663.4 & 20 & 0.055 & $15 \%$ \\
\hline
\end{tabular}

study area, models using only landscape metrics almost always explained more variance than models based on texture measures (Table 5). Only in the case of permanent residents did the textureonly model have a higher adjusted $\mathrm{R}^{2}$ value than the landscape metric-only model. Models including both texture measures and landscape metrics showed consistent but modest increases in adjusted $\mathrm{R}^{2}$ over models including landscape metrics or texture alone, with absolute gains of around 0.04 to 0.08 .

In the Laurentian Mixed Forest, species richness models including only texture variables were superior to landscape metric-only models for every guild (Table 6), with texture-only models outperforming landscape metric-only models by, on average, an absolute adjusted $\mathrm{R}^{2}$ difference of 0.09 for a relative improvement of $34 \%$. This was in sharp contrast to the other ecoregions. When both texture and landscape variables were included in the explanatory variable pool, the resulting models showed strong absolute and relative gains in adjusted $\mathrm{R}^{2}$ values.

In the Eastern Broadleaf Forest (Continental), landscape composition metrics were superior to texture variables for explaining species richness (Table 7), but the differences in adjusted $R^{2}$ values were small (average adjusted $\mathrm{R}^{2}$ values of 0.36 for landscape metrics-only models compared to 0.32 for texture-only models for a 0.03 absolute or $10 \%$ relative increase). Models including both landscape composition metric and texture variables showed modest gains, with an average absolute increase in adjusted $\mathrm{R}^{2}$ of 0.07 and an average relative gain of $18 \%$.

In the Prairie Parkland (Temperate), landscape metric-only models outperformed texture-only models for five out of seven guilds (Table 8). On average, texture-only models had an adjusted $R^{2}$ of 0.27 versus 0.31 for landscape metric-only models, a difference of 0.04. Models including both texture and landscape composition metric variables showed only marginal gains over models that included landscape composition metrics alone, with an average absolute adjusted $\mathrm{R}^{2}$ improvement of 0.04 or a relative improvement of $11 \%$.
Lastly, due to the spatial nature of our study, we expected spatial autocorrelation may have been present in the data. We therefore generated semivariograms of the residuals of all 48 of the final species richness models. Inspection of the semivariograms found no evidence of spatial autocorrelation, and thus no corrective action was necessary.

\section{Discussion}

We found strong evidence supporting our first prediction that image texture measures can explain the variability in avian species richness over broad areas. Our results support earlier studies modeling avian species richness in savanna (Wood et al., 2007) and desert-scrub ecosystems (St-Louis et al., 2009, 2006), as well as studies modeling habitat suitability for individual grassland (Bellis et al., 2008) and forest (Hepinstall \& Sader, 1997) bird species. However, our study expanded texture analysis to a much broader spatial extent $\left(1,498,000 \mathrm{~km}^{2}\right)$ than previously attempted, and we showed that image texture derived from Landsat satellite imagery can explain variability in avian species richness even in habitats with high levels of vertical habitat structure, such as forests.

The broad-extent texture-only multivariate models that we developed had similar explanatory power to models developed for smaller spatial extents (St-Louis et al., 2006; Wood et al., 2007). Our final multivariate models showed that measures of texture can explain up to $51 \%$ of the variability in avian species richness, with most of our final models explaining $20-40 \%$ of the variability. In comparison, texture measures derived from orthophotos within a single habitat type (savanna) yielded univariate $\mathrm{R}^{2}$ values of up to 0.54 (Wood et al., 2007). This was a much stronger relationship than in our univariate models (results not shown), but our multivariate models approached this level of explanatory power. In a $2820 \mathrm{~km}^{2}$ Chihuahuan Desert landscape, multivariate models explained up to $62 \%$ of the variability in avian species richness (St-Louis et al., 2006). This somewhat higher predictive power supports the theory that habitat structure (and therefore texture measures) is more effective at explaining bird species

Table 6

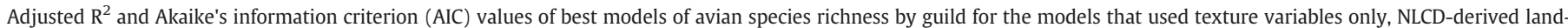
scape metrics only, and a combination of both for the Laurentian Mixed Forest. Bolded $\mathrm{R}^{2}$ and AIC values indicate the superior (texture-only or landscape metric-only) model.

\begin{tabular}{|c|c|c|c|c|c|c|c|c|c|c|c|}
\hline \multirow[t]{2}{*}{ Guild } & \multicolumn{3}{|c|}{$\begin{array}{l}\text { Texture-only } \\
\text { models }\end{array}$} & \multicolumn{3}{|c|}{$\begin{array}{l}\text { Landscape metric-only } \\
\text { models }\end{array}$} & \multicolumn{3}{|c|}{$\begin{array}{l}\text { Texture and landscape metric } \\
\text { models }\end{array}$} & \multirow[b]{2}{*}{ Abs. $\mathrm{R}^{2}$ gain } & \multirow[b]{2}{*}{ Rel. $\mathrm{R}^{2}$ gain } \\
\hline & Adj. $\mathrm{R}^{2}$ & AIC & \# of vars & Adj. $\mathrm{R}^{2}$ & AIC & \# of vars & Adj. $\mathrm{R}^{2}$ & AIC & \# of vars & & \\
\hline All birds & 0.23 & 586.7 & 9 & 0.15 & 592.1 & 3 & 0.31 & 576.4 & 11 & 0.078 & $35 \%$ \\
\hline Forest birds & 0.25 & 548.8 & 5 & 0.21 & 555.1 & 5 & 0.36 & 536.3 & 11 & 0.110 & $43 \%$ \\
\hline Grassland birds & 0.41 & 223.9 & 7 & 0.38 & 227.9 & 5 & 0.53 & 208.9 & 21 & 0.125 & $31 \%$ \\
\hline Shrubland Birds & 0.24 & 234.3 & 8 & 0.15 & 242.5 & 4 & 0.35 & 220.7 & 14 & 0.118 & $50 \%$ \\
\hline Neotropical migrants & 0.20 & 490.8 & 7 & 0.18 & 490.7 & 4 & 0.31 & 480.6 & 14 & 0.107 & $53 \%$ \\
\hline Permanent residents & 0.16 & 244.2 & 5 & 0.07 & 253.6 & 3 & 0.17 & 244.0 & 6 & 0.008 & $5 \%$ \\
\hline Short-distance migrants & 0.19 & 328.3 & 8 & 0.11 & 333.7 & 3 & 0.25 & 322.7 & 11 & 0.057 & $30 \%$ \\
\hline Average & 0.24 & 379.6 & 7 & 0.18 & 385.1 & 3.9 & 0.33 & 369.9 & 12.6 & 0.086 & $36 \%$ \\
\hline
\end{tabular}


Table 7

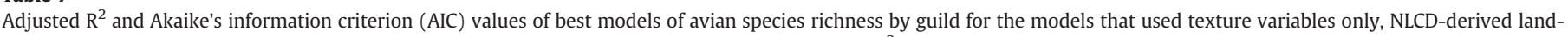

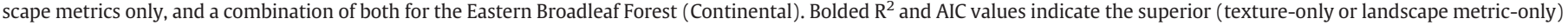
model.

\begin{tabular}{|c|c|c|c|c|c|c|c|c|c|c|c|}
\hline \multirow[t]{2}{*}{ Guild } & \multicolumn{3}{|c|}{$\begin{array}{l}\text { Texture-only } \\
\text { models }\end{array}$} & \multicolumn{3}{|c|}{$\begin{array}{l}\text { Landscape metric-only } \\
\text { models }\end{array}$} & \multicolumn{3}{|c|}{$\begin{array}{l}\text { Texture and landscape metric } \\
\text { models }\end{array}$} & \multirow[b]{2}{*}{ Abs. $\mathrm{R}^{2}$ gain } & \multirow[b]{2}{*}{ Rel. $\mathrm{R}^{2}$ gain } \\
\hline & Adj. $\mathrm{R}^{2}$ & AIC & \# of vars & Adj. $\mathrm{R}^{2}$ & AIC & \# of vars & Adj. $\mathrm{R}^{2}$ & AIC & \# of vars & & \\
\hline All birds & 0.29 & 1383.4 & 8 & 0.32 & 1368.3 & 6 & 0.37 & 1351.7 & 13 & 0.049 & $15 \%$ \\
\hline Forest birds & 0.45 & 1311.9 & 8 & 0.47 & 1296.1 & 7 & 0.53 & 1265.6 & 15 & 0.061 & $13 \%$ \\
\hline Grassland birds & 0.37 & 482.0 & 10 & 0.40 & 465.0 & 9 & 0.49 & 421.1 & 14 & 0.086 & $21 \%$ \\
\hline Shrubland birds & 0.33 & 450.4 & 11 & 0.39 & 423.3 & 10 & 0.48 & 383.2 & 21 & 0.092 & $24 \%$ \\
\hline Neotropical migrants & 0.24 & 1206.4 & 11 & 0.28 & 1185.2 & 5 & 0.32 & 1174.6 & 12 & 0.039 & $14 \%$ \\
\hline Permanent residents & 0.46 & 474.0 & 13 & 0.46 & 468.0 & 8 & 0.54 & 434.2 & 20 & 0.072 & $16 \%$ \\
\hline Short-distance migrants & 0.12 & 578.7 & 6 & 0.19 & $\mathbf{5 5 7 . 0}$ & 8 & 0.25 & 539.9 & 15 & 0.060 & $32 \%$ \\
\hline Average & 0.32 & 841.0 & 9.6 & 0.36 & 823.27 & 7.6 & 0.42 & 795.8 & 15.7 & 0.066 & $18 \%$ \\
\hline
\end{tabular}

richness patterns over small to medium extents than at broader extents (Hutto, 1985).

Another potential source of the slightly higher explanatory power of these smaller-extent studies is the finer spatial resolution of imagery used. These studies used 1-m (St-Louis et al., 2006) and 0.5-m resolution imagery (Wood et al., 2007). At this resolution, individual trees or large shrubs that have an extent of several pixels can be captured by the imagery and canopy gaps or variability in the spatial distribution of shrubs would thus be well sampled. In contrast, our $30-\mathrm{m}$ resolution imagery is too coarse for a single-tree canopy gap to be captured in a single pixel. While small features may still be included in the spectral information, their contribution to image texture is likely weaker than with fine-resolution imagery.

Modeling suitable avian habitat and biodiversity with image texture measures has been effective in habitats with little vertical structure such as grassland (Bellis et al., 2008), desert scrub (St-Louis et al. 2009, 2006), and savanna (Wood et al., 2007). Of the three ecoregions that we analyzed, the Prairie Parkland had the least vertical habitat structure while the Laurentian Mixed Forest had the most. Adjusted $\mathrm{R}^{2}$ values (Table 4) from species richness models were higher in the Laurentian Mixed Forest for all birds, grassland birds, and Neotropical migrants. The Prairie Parkland models had superior adjusted $\mathrm{R}^{2}$ values for forest birds, shrubland birds, permanent residents, and short-distance migrants.

These results refute our second prediction that image texture would perform better in ecosystems with simple vertical structure. Models calculated for an ecoregion dominated by agriculture and grassland performed similarly to models for a forest-dominated ecoregion. While satellite imagery cannot characterize the structure of lower vegetation in forests (Gottschalk et al., 2005), if understory structural characteristics are correlated with canopy features, then useful information may be derived (Estes et al., 2008). It is possible that in our study area understory vegetation features are either less important in explaining patterns of avian species richness than canopy features, or that understory features are sufficiently correlated with the canopy. This is an important finding, as it indicates that, in the context of avian species richness modeling, the usefulness of image texture measures is not limited to habitats with low vertical habitat structure.

A significant shortcoming of landscape metrics is that the landcover classifications on which landscape metrics are based do not retain any information on within-class heterogeneity (Turner et al., 2001). We therefore expected that texture measures would outperform landscape metrics in modeling avian species richness. In addition, we expected some complementarity; that both approaches would characterize some unique information useful in explaining species richness patterns.

Contrary to our third prediction, we found that across our study area (Table 5), and also in the Eastern Broadleaf Forest (Table 7) and the Prairie Parkland (Table 8), models of avian species richness using landscape composition metrics were generally slightly superior to models based on texture measures. This supports the theory that habitat structure is more effective at explaining bird species richness patterns over small to medium extents, and habitat type is more important at broader extents (Hutto, 1985). The notable exception was the Laurentian Mixed Forest (Table 6), where texture models yielded higher adjusted $\mathrm{R}^{2}$ values than landscape metric models for all seven guilds. We speculate that this is due to the predominance of forest in the ecoregion (Table 1), which may render within-forest structure as particularly important in explaining patterns of avian species richness.

Because landscape metrics ignore within-habitat heterogeneity, while texture measures do not, our third prediction also stated that texture measures and landscape metrics would prove complementarity in their ability to explain patterns of avian species richness. For the overall study area and for all three ecoregions, models generated using both NLCD-derived landscape composition metrics and texture measures yielded higher adjusted $\mathrm{R}^{2}$ values than models derived from only landscape composition metrics or only texture measures. The final joint models included a relatively even mix of texture and

Table 8

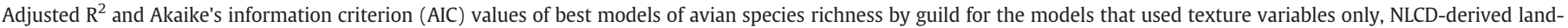

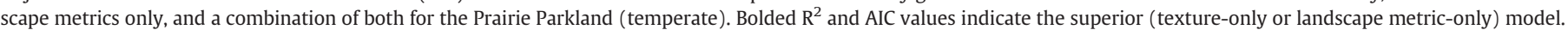

\begin{tabular}{|c|c|c|c|c|c|c|c|c|c|c|c|}
\hline \multirow[t]{2}{*}{ Guild } & \multicolumn{3}{|c|}{$\begin{array}{l}\text { Texture-only } \\
\text { models }\end{array}$} & \multicolumn{3}{|c|}{$\begin{array}{l}\text { Landscape metric-only } \\
\text { models }\end{array}$} & \multicolumn{3}{|c|}{$\begin{array}{l}\text { Texture and landscape metric } \\
\text { models }\end{array}$} & \multirow[b]{2}{*}{ Absolute $\mathrm{R}^{2}$ gain } & \multirow[b]{2}{*}{ Percent $\mathrm{R}^{2}$ gain } \\
\hline & Adj. $\mathrm{R}^{2}$ & AIC & \# of vars & Adj. $R^{2}$ & AIC & \# of vars & Adj. $\mathrm{R}^{2}$ & AIC & \# of vars & & \\
\hline All birds & 0.19 & 728.8 & 4 & 0.24 & 719.0 & 6 & 0.27 & 715.4 & 9 & 0.030 & $12 \%$ \\
\hline Forest birds & 0.29 & 688.9 & 4 & 0.36 & 675.5 & 7 & 0.40 & 673.4 & 17 & 0.044 & $12 \%$ \\
\hline Grassland birds & 0.20 & 200.8 & 8 & 0.28 & 184.1 & 8 & 0.30 & 186.3 & 15 & 0.019 & $7 \%$ \\
\hline Shrubland birds & 0.32 & 255.9 & 12 & 0.28 & 256.4 & 3 & 0.36 & 247.2 & 13 & 0.039 & $12 \%$ \\
\hline Neotropical migrants & 0.15 & 603.9 & 9 & 0.23 & 585.6 & 7 & 0.27 & 584.3 & 14 & 0.036 & $16 \%$ \\
\hline Permanent residents & 0.51 & 316.9 & 12 & 0.56 & 296.3 & 8 & 0.59 & 286.0 & 9 & 0.030 & $5 \%$ \\
\hline Short-distance migrants & 0.24 & 254.7 & 8 & 0.19 & 262.0 & 4 & 0.29 & 244.4 & 8 & 0.047 & $20 \%$ \\
\hline Average & 0.27 & 435.7 & 8.1 & 0.31 & 425.5 & 6.1 & 0.35 & 419.6 & 12.1 & 0.035 & $11 \%$ \\
\hline
\end{tabular}


landscape variables (results not shown). This indicates some level of complementarity, but we caution that this could potentially result from model over-fitting. For the overall study area (Table 5), the Eastern Broadleaf Forest (Table 7), and the Prairie Parkland (Table 8), the improvement in adjusted $\mathrm{R}^{2}$ was small, and the joint models were not very parsimonious (full study region: average of 20.0 variables per model; Eastern Broadleaf Forest: 17.4 variables per model; Prairie Parkland: 12.4 variables per model).

However, in the Laurentian Mixed Forest, four of the seven landscape and texture models showed absolute improvement in adjusted $\mathrm{R}^{2}$ greater than 0.10 , and six of the seven models had relative adjusted $\mathrm{R}^{2}$ improvement greater than $30 \%$ (Table 6). Gains of this magnitude cannot be explained by over-fitting alone, and we thus conclude that at least in the Laurentian Mixed Forest, measures of image texture and landscape metrics are complementary.

Because measures of image texture characterize spatial heterogeneity in landcover and vegetation, two key components of avian habitat, our fourth prediction was that our texture measure models would perform better for guilds based on habitat preference compared with guilds based on migratory habit (Fig. 3). This prediction held overall with texture models explaining, on average, $32 \%$ of the variation in species richness of habitat guilds and $26 \%$ of variation of migratory guilds. We do note, however, that the strongest model overall was for species richness of permanent residents, though it was followed by the three habitat guilds.

We were also surprised to see which habitat guilds showed the strongest models in certain ecoregions (Fig. 3). Texture measurebased models explained the most variation in grassland bird species richness in the Laurentian Mixed Forest (adjusted $R^{2}=0.41$ ) followed by the Eastern Broadleaf Forest (0.37), and the Prairie Parkland (0.20). Texture measures explained twice as much of the variation in grassland bird species richness in the most forested region than in the region with the most agriculture and grassland. Similarly, models of forest bird species richness were strongest in the Eastern Broadleaf Forest (adjusted $\mathrm{R}^{2}=0.45$ ), then the Prairie Parkland (0.29), then the Laurentian Mixed Forest (0.25). Again, models of

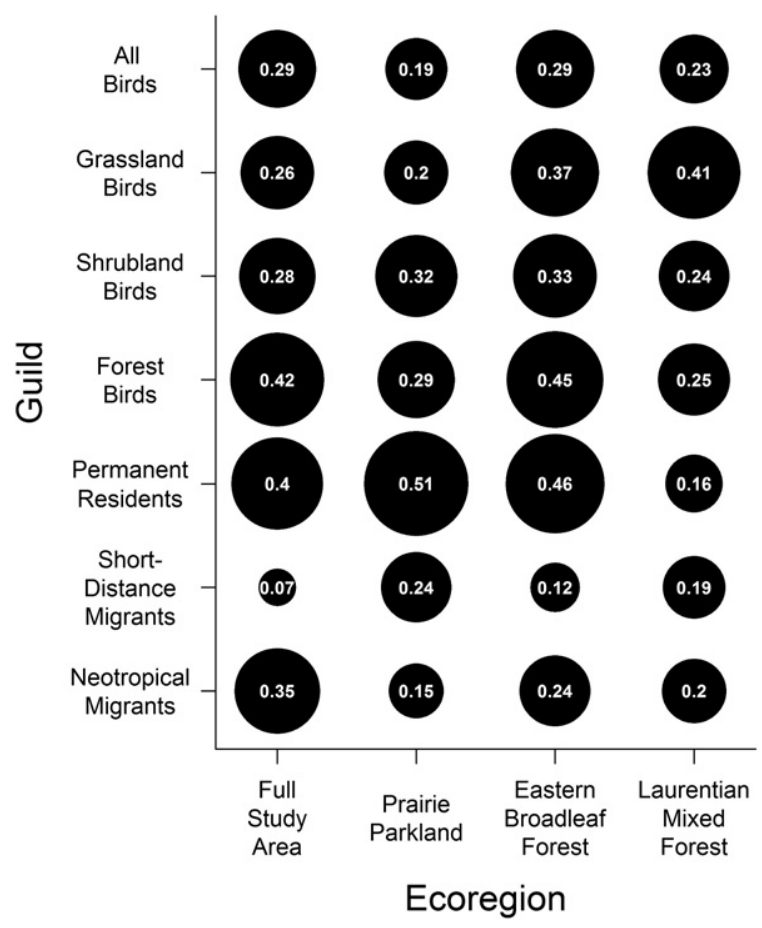

Fig. 3. Adjusted $R^{2}$ values of best multivariate models of avian species richness based on measures of image texture for each avian guild and ecoregion. Circle diameter is proportional to adjusted $\mathrm{R}^{2}$ value. forest bird species richness were strongest in a moderately forested ecoregion and weakest in the most heavily forested ecoregion. This suggests that it is easier to model species richness of certain groups of birds in areas where there is less suitable habitat for them. For example, in a grassland area with only a few small "islands" of forest, forest bird richness will be very low in the grassland areas and very high in the forest area. On the other hand, in a completely forested area, it will be harder to predict which areas of forest will have the highest forest bird richness since the entire area is potentially suitable habitat for forest birds.

An important caveat for this study, as mentioned earlier, is that while all our satellite images were acquired during the growing season, they were not all from the same phenological stage. In most remote sensing analyses, it is ideal for imagery to have the same acquisition date, as image phenological stage may affect analysis, including image texture analysis (Culbert et al., 2009). However, when analyzing very large areas, this is not always possible. This likely introduced extraneous variability into our texture measurements, and had all our images been acquired at the same phenological stage, the relationships between image texture measures and avian species richness would likely have been even stronger.

The use of image texture measures for habitat and biodiversity analyses has two potential drawbacks: significant computational requirements and difficulties in interpreting the ecological relevance of specific texture measures. First, calculations of second-order image texture are computationally much more demanding than other common remote sensing data analyses. While this challenge will become less significant as computing power continues to increase, it is currently non-trivial to calculate second-order texture measures over a broad extent. Second, interpreting the ecological meaning of specific texture measures is challenging. Many of the texture measures, especially second-order measures, are difficult to conceptualize in terms of what they represent "on the ground". This means that texture measures provide only limited additional insights into the ecology of birds. However, there are many applications, such as conservation planning, for which the variables selected may matter much less than the quality of the output map, and texture metrics can be valuable for such tasks.

In summary, our study showed that image-texture can be an important tool to explain avian species richness patterns over broad areas. Image texture measures were effective in modeling species richness for several avian guilds, and over varied habitats, ranging from grassland to forest. In particular, texture measures showed superior performance to landscape composition metrics in the most forested ecoregion, and the two types of measures showed strong complementarity. However, in about three-fourths of our models, texture measures had slightly less explanatory power than landscape composition metrics. For this reason the simultaneous use of texture measures and landscape metrics should be considered. The use of image texture measures is also highly useful when an accurate landcover map is unavailable for a given study area, or when the classes of existing maps do not capture the ecological attributes relevant to the study. The use of image texture is a valuable approach for characterizing structure from continuous data sources and should therefore be considered in the spatial modeling of species diversity and habitat suitability for conservation planning.

\section{Acknowledgments}

The Authors would like to thank D. Helmers for technical assistance and G. Thain and the University of Wisconsin-Madison Center for High-Throughput Computing for substantial data processing assistance. Two anonymous reviews provided feedback, which greatly improved the manuscript. This work was supported by the NASA Biodiversity Program, and a NASA Earth Systems Science Fellowship to P. D. 
Culbert. T. P. Albright acknowledges support from National Science Foundation, Cooperative Agreement EPS-0814372.

\section{References}

Albright, T. P., Pidgeon, A. M., Rittenhouse, C. D., Clayton, M. K., Flather, C. H., Culbert P.D., et al. (2010). Effects of drought on avian community structure. Global Change Biology, 16, 2158-2170.

Albright, T. P., Pidgeon, A. M., Rittenhouse, C. D., Clayton, M. K., Flather, C. H., Culbert, P.D., et al. (2011). Heat waves measured with MODIS land surface temperature data predict changes in avian community structure. Remote Sensing of Environment, $115,245-254$.

Atauri, J. A., \& de Lucio, J. V. (2001). The role of landscape structure in species richness distribution of birds, amphibians, reptiles and lepidopterans in Mediterranean landscapes. Landscape Ecology, 16, 147-159.

Bailey, R. G. (1995). Description of the ecoregions of the United States. : United States Department of Agriculture.

Baraldi, A., \& Parmiggiani, F. (1995). An investigation of the textural characteristics associated with gray-level co-occurrence matrix statistical parameters. IEEE Transactions on Geoscience and Remote Sensing, 33, 293-304.

Bellis, L. M., Pidgeon, A. M., Radeloff, V. C., St-Louis, V., Navarro, J. L., \& Martella, M. B. (2008). Modeling habitat suitability for Greater Rheas based on satellite image texture. Ecological Applications, 18, 1956-1966.

Bergen, K. M., Goetz, S. J., Dubayah, R. O., Henebry, G. M., Hunsaker, C. T., Imhoff, M. L., et al. (2009). Remote sensing of vegetation 3-D structure for biodiversity and habitat: Review and implications for LiDAR and radar spaceborne missions. Journa of Geophysical Research-Biogeosciences, 114, G00E06.

Buckton, S. T., \& Ormerod, S. J. (2002). Global patterns of diversity among the specialist birds of riverine landscapes. Freshwater Biology, 47, 695-709.

Clawges, R., Vierling, K., Vierling, L., \& Rowell, E. (2008). The use of airborne LiDAR to assess avian species diversity, density, and occurrence in a pine. Remote Sensing of Environment, 112, 2064-2073.

Coburn, C. A., \& Roberts, A. C. B. (2004). A multiscale texture analysis procedure for improved forest stand classification. International Journal of Remote Sensing, 25, 4287-4308.

Cody, M. L. (1981). Habitat selection in birds - The roles of vegetation structure, competitors, and productivity. Bioscience, 31, 107-113.

Culbert, P. D., Pidgeon, A. M., St-Louis, V., Bash, D., \& Radeloff, V. C. (2009). The impact of phenological variation on texture measures of remotely sensed imagery. IEEE Journal of Selected Topics in Applied Earth Observations and Remote Sensing, 2, 299-309.

Daly, C., Halbleib, M., Smith, J. I., Gibson, W. P., Doggett, M. K., Taylor, G. H., et al. (2008). Physiographically sensitive mapping of climatological temperature and precipitation across the conterminous United States. International Journal of Climatology, 28, 2031-2064.

Donovan, T. M., \& Flather, C. H. (2002). Relationships among north American songbird trends, habitat fragmentation, and landscape occupancy. Ecological Applications, 12, 364-374.

Estes, L. D., Okin, G. S., Mwangi, A. G., \& Shugart, H. H. (2008). Habitat selection by a rare forest antelope: A multi-scale approach combining field data and imagery from three sensors. Remote Sensing of Environment, 112, 2033-2050.

Estes, L. D., Reillo, P. R., Mwangi, A. G., Okin, G. S., \& Shugart, H. H. (2010). Remote sensing of structural complexity indices for habitat and species distribution modeling. Remote Sensing of Environment, 114, 792-804.

Farina, A. (1997). Landscape structure and breeding bird distribution in a sub-Mediterranean agro-ecosystem. Landscape Ecology, 12, 365-378.

Flather, C. H., \& Sauer, J. R. (1996). Using landscape ecology to test hypotheses about large-scale abundance patterns in migratory birds. Ecology, 77, 28-35.

Franklin, S. E., Hall, R. J., Moskal, L. M., Maudie, A. J., \& Lavigne, M. B. (2000). Incorporating texture into classification of forest species composition from airborne multispectral images. International Journal of Remote Sensing, 21, 61-79.

Franklin, S. E., Maudie, A. J., \& Lavigne, M. B. (2001). Using spatial co-occurrence texture to increase forest structure and species composition classification accuracy. Photogrammetric Engineering and Remote Sensing, 67, 849-855.

Gaston, K. J., Blackburn, T. M., \& Goldewijk, K. K. (2003). Habitat conversion and global avian biodiversity loss. Proceedings of the Royal Society B: Biological Sciences, 270, 1293-1300.

Goetz, S., Steinberg, D., Dubayah, R., \& Blair, B. (2007). Laser remote sensing of canopy habitat heterogeneity as a predictor of bird species richness in an eastern temperate forest, USA. Remote Sensing of Environment, 108, 254-263.

Gottschalk, T. K., Huettmann, F., \& Ehlers, M. (2005). Thirty years of analysing and modelling avian habitat relationships using satellite imagery data: A review. International Journal of Remote Sensing, 26, 2631-2656.

Haralick, R. M. (1979). Statistical and structural approaches to texture. Proceedings of the IEEE, 67, 786-804.

Haralick, R. M., Shanmuga, K., \& Dinstein, I. (1973). Textural features for image classification. IEEE Transactions on Systems, Man, and Cybernetics, SMC3, 610-621.

Hepinstall, J. A., \& Sader, S. A. (1997). Using Bayesian statistics, Thematic Mapper satellite imagery, and breeding bird survey data to model bird species probability of occurrence in Maine. Photogrammetric Engineering and Remote Sensing, 63, $1231-1237$.

Hines, J. E., Boulinier, T., Nichols, J. D., Sauer, J. R., \& Pollock, K. H. (1999). COMDYN Software to study the dynamics of animal communities using a capture-recapture approach. Bird Study, 46, 209-217.
Homer, C., Huang, C. Q., Yang, L. M., Wylie, B., \& Coan, M. (2004). Development of a 2001 national land-cover database for the United States. Photogrammetric Engineering and Remote Sensing, 70, 829-840.

Hudak, A. T., \& Wessman, C. A. (1998). Textural analysis of historical aerial photography to characterize woody plant encroachment in South African savanna. Remote Sensing of Environment, 66, 317-330.

Huete, A., Didan, K., Miura, T., Rodriguez, E. P., Gao, X., \& Ferreira, L. G. (2002). Overview of the radiometric and biophysical performance of the MODIS vegetation indices. Remote Sensing of Environment, 83, 195-213.

Hutto, R. L. (1985). Habitat selection by nonbreeding migratory birds. In M. L. Cody (Ed.), Habitat selection in birds (pp. 455-476). NY: Academic Press.

Innes, J. L., \& Koch, B. (1998). Forest biodiversity and its assessment by remote sensing. Global Ecology and Biogeography, 7, 397-419.

Kayitakire, F., Hamel, C., \& Defourny, P. (2006). Retrieving forest structure variables based on image texture analysis and IKONOS-2 imagery. Remote Sensing of Environment, 102, 390-401.

Kerr, J. T., \& Ostrovsky, M. (2003). From space to species: Ecological applications for remote sensing. Trends in Ecology \& Evolution, 18, 299-305.

Kéry, M., \& Schmid, H. (2004). Monitoring programs need to take into account imperfect species detectability. Basic and Applied Ecology, 5, 65-73.

Kondo, T., \& Nakagoshi, N. (2002). Effect of forest structure and connectivity on bird distribution in a riparian landscape. Phytocoenologia, 32, 665-676.

Lesak, A. A., Radeloff, V. C., Hawbaker, T. J., Pidgeon, A. M., Gobakken, T., \& Contrucci, K. (2011). Modeling forest songbird species richness using LiDAR-derived measures of forest structure. Remote Sensing of Environment, 115, 2823-2835.

Luoto, M., Virkkala, R., Heikkinen, R. K., \& Rainio, K. (2004). Predicting bird species richness using remote sensing in boreal agricultural-forest mosaics. Ecological Applications, 14, 1946-1962.

MacArthur, R. H. (1958). Population ecology of some warblers of Northeastern coniferous forests. Ecology, 39, 599-619.

MacArthur, R. H. (1972). Geographical ecology: Patterns in the distribution of species. : Harper \& Row.

MacArthur, R. H., \& MacArthur, J. W. (1961). On bird species diversity. Ecology, 42, 594-598.

MacArthur, R., Recher, H., \& Cody, M. (1966). On the relation between habitat selection and species diversity. The American Naturalist, 100, 319-332.

Masek, J. G., Vermote, E. F., Saleous, N. E., Wolfe, R., Hall, F. G., Huemmrich, K. F., et al. (2006). A Landsat surface reflectance dataset for North America, 1990-2000. IEEE Geoscience and Remote Sensing Letters, 3, 68-72.

Myers, N., Mittermeier, R. A., Mittermeier, C. G., da Fonseca, G. A. B., \& Kent, J. (2000). Biodiversity hotspots for conservation priorities. Nature, 403, 858.

Myneni, R. B., Hoffman, S., Knyazikhin, Y., Privette, J. L., Glassy, J., Tian, Y., et al. (2002). Global products of vegetation leaf area and fraction absorbed PAR from year one of MODIS data. Remote Sensing of Environment, 83, 214-231.

Myneni, R. B., Nemani, R. R., \& Running, S. W. (1997). Estimation of global leaf area index and absorbed par using radiative transfer models. IEEE Transactions on Geoscience and Remote Sensing, 35, 1380-1393.

Nagendra, H. (2001). Using remote sensing to assess biodiversity. International Journal of Remote Sensing, 22, 2377-2400.

Nichols, J. D., Boulinier, T., Hines, J. E., Pollock, K. H. \& Sauer, J. R. (1998). Inference methods for spatial variation in species richness and community composition when not all species are detected. Conservation Biology, 12, 1390-1398.

Peterjohn, B. G., \& Sauer, J. R. (1999). Population status of North American grassland birds from the North American breeding bird survey, 1966-1996. In P. D. Vickery, \& J. R. Herkert (Eds.), Ecology and conservation of grassland birds of the Western Hemisphere (pp. 27-44). Camarillo, CA: Cooper Ornithological Society.

Pidgeon, A. M., Radeloff, V. C., Flather, C. H., Lepczyk, C. A., Clayton, M. K., Hawbaker, T.J., et al. (2007). Associations of forest bird species richness with housing and landscape patterns across the USA. Ecological Applications, 17, 1989-2010.

R Development Core Team. (2009). R: A language and environment for statistical computing.

Rappole, J. H. (1995). The ecology of migrant birds. Washington, D.C.: Smithsonian Institute Press.

Rittenhouse, C. D., Pidgeon, A. M., Albright, T. P., Culbert, P. D., Clayton, M. K., Flather, C.H., et al. (2010). Avifauna response to hurricanes: Regional changes in community similarity. Global Change Biology, 16, 905-917.

Rosenzweig, M. L. (1995). Species diversity in space and time. : Cambridge University Press.

Roy, P. S. (2003). Biodiversity conservation - Perspective from space. National Academy Science Letters - India, 26, 169-184.

Seavy, N. E., Viers, J. H., \& Wood, J. K. (2009). Riparian bird response to vegetation structure: A multiscale analysis using LiDAR measurements of canopy height. Ecological Applications, 19, 1848-1857.

Shannon, C. E. (1948). A mathematical theory of communication. Bell System Technical Journal, 27, 379-423 (and 623-656).

Stickler, C. M., \& Southworth, J. (2008). Application of multi-scale spatial and spectral analysis for predicting primate occurrence and habitat associations in Kibale National Park, Uganda. Remote Sensing of Environment, 112, 2170-2186.

St-Louis, V., Pidgeon, A. M., Clayton, M. K., Locke, B. A., Bash, D., \& Radeloff, V. C. (2009). Satellite image texture and a vegetation index predict avian biodiversity in the Chihuahuan Desert of New Mexico. Ecography, 32, 468-480.

St-Louis, V., Pidgeon, A. M., Radeloff, V. C., Hawbaker, T. J., \& Clayton, M. K. (2006). Highresolution image texture as a predictor of bird species richness. Remote Sensing of Environment, 105, 299-312.

Sutherland, G. D., Harestad, A. S., Price, K., \& Lertzman, K. P. (2000). Scaling of natal dispersal distances in terrestrial birds and mammals. Conservation Ecology, 4, 16. 
Tews, J., Brose, U., Grimm, V., Tielborger, K., Wichmann, M. C., Schwager, M., et al. (2004). Animal species diversity driven by habitat heterogeneity. Journal of Biogeography, 31, 79-92. The MathWorks, I. (1984-2010). Matlab. , R2010a.

Tittler, R., Villard, M., \& Fahrig, L. (2009). How far do songbirds disperse? Ecography, 32, 1051-1061.

Tucker, C. J., Grant, D. M., \& Dykstra, J. D. (2004). NASA's global orthorectified landsat data set. Photogrammetric Engineering and Remote Sensing, 70, 313-322.

Turner, M. G., Gardner, R. H., \& O'Neill, R. V. (2001). Landscape ecology in theory and practice. New York: Springer.

Turner, D. P., Ritts, W. D., Cohen, W. B., Gower, S. T., Running, S. W., Zhao, M., et al. (2006). Evaluation of MODIS NPP and GPP products across multiple biomes. Remote Sensing of Environment, 102, 282-292.

Turner, W., Spector, S., Gardiner, N., Fladeland, M., Sterling, E., \& Steininger, M. (2003). Remote sensing for biodiversity science and conservation. Trends in Ecology \&' Evolution, 18, 306-314.

Tuttle, E. M., Jensen, R. R., Formica, V. A., \& Gonser, R. A. (2006). Using remote sensing image texture to study habitat use patterns: A case study using the polymorphic whitethroated sparrow (Zonotrichia albicollis). Global Ecology and Biogeography, 15, 349-357.
Wan, Z. M., Zhang, Y. L., Zhang, Q. C., \& Li, Z. L. (2002). Validation of the land-surface temperature products retrieved from Terra Moderate Resolution Imaging Spectroradiometer data. Remote Sensing of Environment, 83, 163-180.

Wiens, J. A. (1974). Habitat heterogeneity and avian community structure in NorthAmerican grasslands. American Midland Naturalist, 91, 195-213.

Willson, M. F. (1974). Avian community organization and habitat structure. Ecology, 55, 1017-1029.

Wood, E. M., Pidgeon, A. M., \& Radeloff, V. C. (2007). Comparing image texture from infrared versus panchromatic aerial photographs for predicting avian species richness in a Midwest prairie savanna. 68th Midwest Fish and Wildlife Conference. December 9-12, 2007. Madison, WI.

Wulder, M. A., LeDrew, E. F., Franklin, S. E., \& Lavigne, M. B. (1998). Aerial image texture information in the estimation of northern deciduous and mixed wood forest leaf area index (LAI). Remote Sensing of Environment, 64, 64-76.

Wunderle, A. L., Franklin, S. E., \& Guo, X. G. (2007). Regenerating boreal forest structure estimation using SPOT-5 pan-sharpened imagery. International Journal of Remote Sensing, 28, 4351-4364. 